\title{
CYP1B1, but not CYP1A1, is downregulated by promoter methylation in colorectal cancers
}

\author{
WATARU HABANO ${ }^{1}$, TOSHIE GAMO ${ }^{1}$, TAMOTSU SUGAI ${ }^{2}$, KOKI OTSUKA ${ }^{3}$, \\ GO WAKABAYASHI ${ }^{3}$ and SHOGO OZAWA ${ }^{1}$
}

\begin{abstract}
${ }^{1}$ Department of Pharmacodynamics and Molecular Genetics, School of Pharmacy, Iwate Medical University, 2-1-1 Nishitokuta, Yahaba-Cho, Shiwa-Gun, Iwate 028-3694; ${ }^{2}$ Division of Molecular Diagnostic Pathology, Department of Pathology, ${ }^{3}$ Department of Surgery, School of Medicine, Iwate Medical University, Iwate Medical University, 19-1 Uchimaru, Morioka, Iwate 020-8505, Japan
\end{abstract}

Received November 11, 2008; Accepted January 5, 2009

DOI: 10.3892/ijo_00000235

\begin{abstract}
Cytochrome P450 (CYP) 1A1 (CYP1A1) and CYP1B1, dioxin-inducible CYP1s, are associated with carcinogenesis in extrahepatic tissues. CYP1B1 is featured in carcinogenesis of hormone-responsive tissues, where the CYP1B1 level is considerably high. Although aberrant expression of these enzymes is also observed in cancers that are not related to hormone response, their roles in carcinogenesis are not yet fully understood. We examined DNA methylation status of the $\mathrm{CpG}$ islands within the 5'flanking region of the $C Y P 1 B 1$ and $C Y P 1 A 1$ genes in 7 colorectal cancer cell lines and 40 primary colorectal cancers. By bisulfite-modified direct sequencing, $C Y P 1 B 1$ gene methylation was detected in 2 cell lines (SW48 and Caco-2) and $2(5 \%)$ cancers, but not in corresponding normal tissues. Treatment of the cells with 5-aza-2'-deoxycytidine revealed a clear increase in the CYP1B1 mRNA levels in SW48 and Caco-2 cells, while the amount of methylated alleles decreased. Only HT29 cells showed a clear increase in CYP1A1 mRNA, although there were no apparent differences in methylation status among these cell lines. None of these cell lines showed significant change in mRNA levels of aryl hydrocarbon receptor (AhR) and AhR nuclear translocator (ARNT), which are known to directly activate $C Y P 1$ transcription. This observation suggested that expression of CYP1B1, but not CYP1A1, was downregulated by promoter methylation rather than decreased expression of AhR/ARNT. In conclusion, $\mathrm{CpG}$ methylation of the $C Y P 1 B 1$ promoter region epigenetically regulates $\mathrm{CY}$ 1B 1 expression during
\end{abstract}

Correspondence to: Dr Wataru Habano, Department of Pharmacodynamics and Molecular Genetics, School of Pharmaceutical Sciences, Iwate Medical University, 2-1-1 Nishitokuta, Yahaba-Cho, Shiwa-Gun, Iwate 028-3694, Japan

E-mail:whabano@iwate-med.ac.jp

Key words: CYP1B1, DNA methylation, gene regulation development of some colorectal cancers. Moreover, cancers with aberrant CYP1B1 expression might show altered response to procarcinogen metabolism and chemotherapy.

\section{Introduction}

Human cytochrome P450 (CYP) 1A1 (CYP1A1) and CYP1B1, dioxin-inducible members of the CYP family, activate procarcinogens, including bezo[a]pyrene and 7,12-dimethylbenz $[a]$ anthracene (1-3). The expression of CYP1 family is controlled by binding of several transcription factors, such as aryl hydrocarbon receptor (AhR) and AhR nuclear translocator (ARNT) heterodimer, with a particular tissue specificity (4-7). CYP1B1 is also known to catalyze the hydroxylation of $17 \beta$-estradiol (8), and is associated with carcinogenesis in hormone-mediated cancers, including breast and prostate cancers $(9,10)$. On the other hand, aberrant expression of the CYP1B1 is observed in wide variety of cancers, independent of hormone response (11). Colorectal cancers generally overexpress CYP1B1, but with a large heterogeneity $(12,13)$. In addition, certain genetic polymorphisms of the CYP1B1 were also associated with incidences of colorectal cancers (14). These observations prompt us to speculate that CYP1B1 plays a possible role in colorectal carcinogenesis. However, the mechanisms regulating tissue-specific and cancer-specific expression of CYP1B1 and their roles in carcinogenesis are not yet clarified.

Aberrant expression of cancer-related genes (oncogenes and tumor suppressor genes) is caused by epigenetic mechanisms during carcinogenesis. One of the well-characterized mechanisms is DNA methylation of the promoter $\mathrm{CpG}$ islands, which leads to a transcriptional downregulation of tumor suppressor genes (15). Recent studies demonstrated that some drug-metabolizing enzyme genes also have $\mathrm{CpG}$ islands in their promoter region and can be downregulated by DNA methylation in cancers (16). CYP1B1 in prostate cancers was reported to be overexpressed through the $C Y P 1 B 1$ promoter hypomethylation (17). These observation prompted us to examine whether $C Y P 1 B 1$ promoter methylation in normal colon mucosa is lost during colon carcinogenesis to overexpress CYP1B1. 
(a)
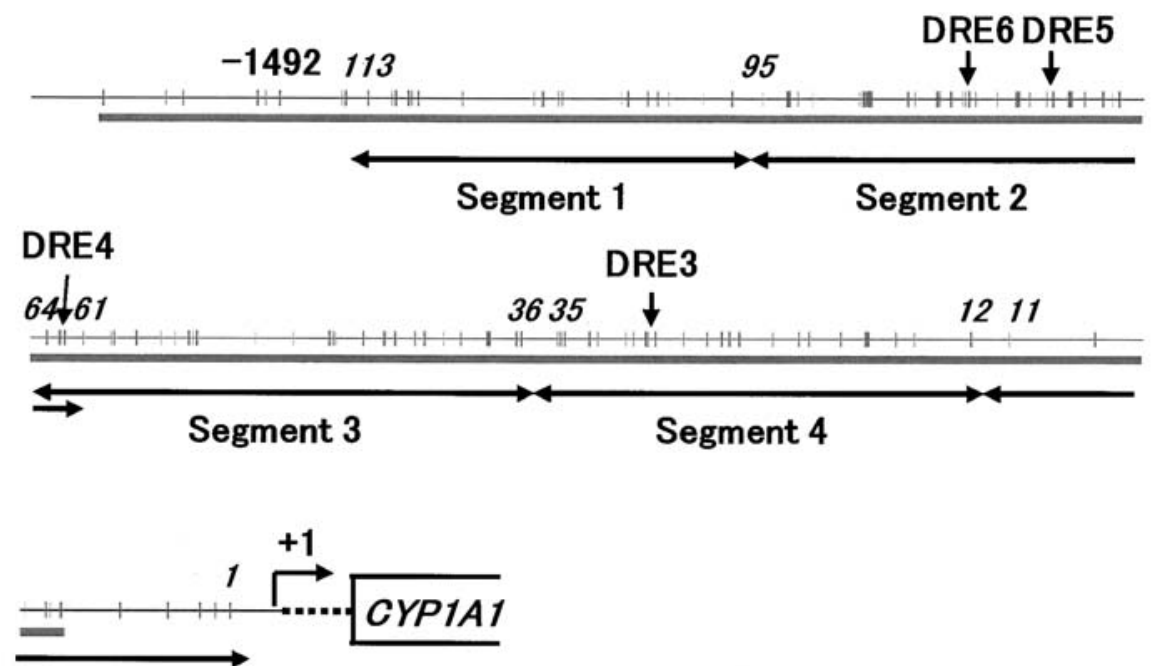

Segment 5

(b)
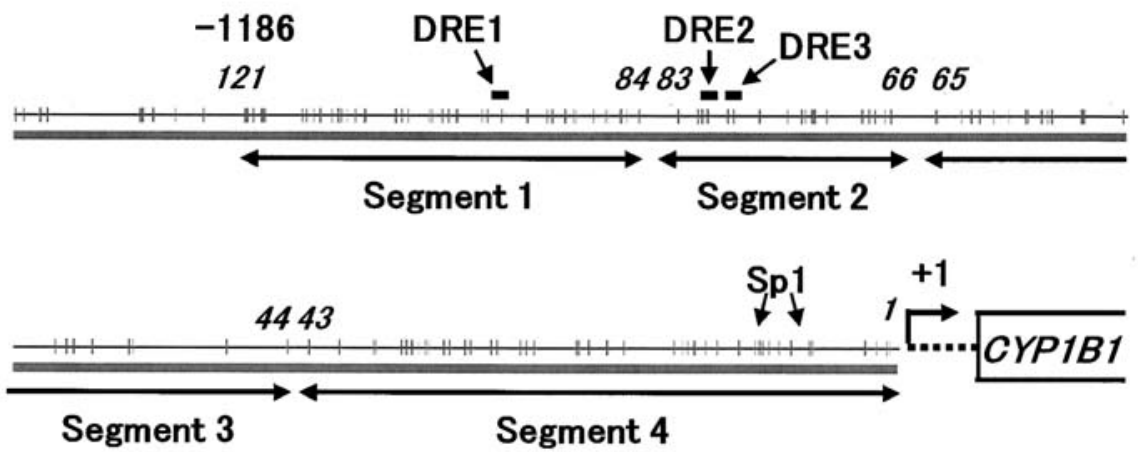

I CpG site

Figure 1. Schematic diagram of locations of the $\mathrm{CpG}$ sites (vertical bars), transcription start site (curved arrow) and potential binding sites of transcription factors (Sp1, DREs) within the 5' prime region of: (a), CYP1A1; and (b), CYP1B1 gene. CpG sites are numbered in italics sequentially starting from the transcription start site with an increasing order to the upstream direction. For bisulfite sequencing analysis, 1.5 and $1.2 \mathrm{~kb}$ upstream regions (including 113 and $121 \mathrm{CpG}$ sites) of the $C Y P 1 A 1$ and $C Y P 1 B 1$ gene were divided into five and four segments, respectively.

In order to clarify the mechanisms by which cancers can acquire altered expression of the CYP1A1 and CYP1B1, we focused on epigenetic mechanisms such as DNA methylation. We examined DNA methylation status in the 5' upstream region of the $C Y P 1 B 1$ and $C Y P I A 1$ genes in colorectal cancer cell lines and primary cancers. If DNA methylation is involved in these cancers, these enzymes would be associated with cancer development and affects the chemosensitivity of cancer cells through epigenetic mechanisms.

\section{Materials and methods}

Cell lines and tissue samples. Human colorectal cancer cell lines used in this study (HT29, HCT116, DLD-1, LoVo, SW48, SW620 and Caco-2) were purchased from DS Pharma Biomedical Co., Ltd. (Osaka, Japan). HT29, HCT116 and SW48 cells were cultured in McCoy's 5A medium (Invitrogen
Corp., Carlsbad, CA). DLD-1 and LoVo cells were cultured in Ham's F12 medium (Invitrogen). SW620 cells were cultured in Leibovitz L-15 medium (Invitrogen). Caco-2 cells were cultured in E-MEM medium (Invitrogen). All mediums were supplemented with $10 \%$ fetal bovine serum (FBS, HyClone Laboratories Inc., Logan, UT). These cells were cultured at $37^{\circ} \mathrm{C}$ under an atmosphere of $5 \% \mathrm{CO}_{2}$.

All clinical tissue samples were obtained from patients following provision of informed consent according to the Ethics Committee guidelines of Iwate Medical University, Japan. Forty pairs of cancer and adjacent normal mucosa were excised from surgical specimens of colorectal cancers and then subjected to crypt isolation (18) to obtain cancer and normal epithelia without stromal cells.

Treatment with 5-aza-2'-deoxycytidine. HT29, HCT116, SW48 and Caco-2 cells were seeded at a concentration of 
Table I. Primers used for DNA methylation analysis.

\begin{tabular}{|c|c|c|c|c|}
\hline Gene & Segment & Primer sequence $\left(5^{\prime}-3^{\prime}\right)$ & $\begin{array}{c}\text { Annealing } \\
\text { temperature }\left({ }^{\circ} \mathrm{C}\right)\end{array}$ & $\begin{array}{l}\text { Product } \\
\text { size (bp) }\end{array}$ \\
\hline \multirow[t]{8}{*}{$C Y P 1 B 1$} & $1 \mathrm{~F}$ & GGTTTTTTTATAAAGGGAGGGTTT & 55 & 310 \\
\hline & $1 \mathrm{R}$ & АСТССААТСАТАТСССТАААС & & \\
\hline & $2 \mathrm{~F}$ & GTTTAGGGATATGATTGGAGT & 50 & 189 \\
\hline & $2 \mathrm{R}$ & ACTAAAAAAACCTAAAAAAACTAAC & & \\
\hline & $3 \mathrm{~F}$ & GTTAGTTTTTTTAGGTTTTTTTAGT & 55 & 343 \\
\hline & $3 \mathrm{R}$ & CCAATATAATAACAACRATTTACCT & & \\
\hline & $4 \mathrm{~F}$ & ATTAGGGGYGTTGTGAGGTAAA & 60 & 432 \\
\hline & $4 \mathrm{R}$ & TCССАСТСССАСТССААААТ & & \\
\hline \multirow[t]{10}{*}{ CYP1A1 } & $1 \mathrm{~F}$ & GGGATTATTTTTTGGTTTGGATTAG & 50 & 303 \\
\hline & $1 \mathrm{R}$ & TCTAAATCTACRTATAACTTCTAACCT & & \\
\hline & $2 \mathrm{~F}$ & AGGTTAGAAGTTATAYGTAGATTTAGA & 55 & 310 \\
\hline & $2 \mathrm{R}$ & САТСССТСТААААААСАААААТС & & \\
\hline & $3 \mathrm{~F}$ & GATTTTTGTTTTTTAGAGGGATG & 60 & 369 \\
\hline & $3 \mathrm{R}$ & ACTAААССТАТСССССААААСС & & \\
\hline & $4 \mathrm{~F}$ & GGTTTTGGGGGATAGGTTTAGT & 60 & 329 \\
\hline & $4 \mathrm{R}$ & TCCCAAAAACAATACAAAACCCAAC & & \\
\hline & $5 \mathrm{~F}$ & GTTGGGTTTTGTATTGTTTTTGGGA & 55 & 270 \\
\hline & $5 \mathrm{R}$ & TAAAAACACTACCACСТTTATAAAC & & \\
\hline
\end{tabular}

F, forward primer; $\mathrm{R}$, reverse primer.

$1 \times 10^{5}$ cells on a $100 \mathrm{~mm}$ dish. The next day, treatment of cells with $0,0.5$ or $5 \mu \mathrm{M} 5$-aza-2'-deoxycytidine (5-aza-dC) (Sigma Chemical, St. Louis, MO) was started, and 5-aza-dC was removed by changing medium $24 \mathrm{~h}$ later. The cells were harvested 4 days after removal of 5-aza-dC for DNA and RNA extraction.

DNA methylation analysis. $\mathrm{CpG}$ islands within the 5'-flanking region of the $C Y P 1 B 1$ and $C Y P 1 A 1$ genes were screened by CpG Island Searcher program (http://cpgislands.usc.edu/). The $\mathrm{CpG}$ islands encompassed 1.2 and $1.5 \mathrm{~kb}$ upstream region of the transcription start sites of the CYPIAl and $C Y P 1 B 1$ genes, respectively. For PCR amplifications, these regions of the $C Y P 1 A 1$ and $C Y P 1 B 1$ genes were divided into five and four segments, respectively (Fig. 1). All primer sequences and PCR conditions used for methylation analysis are shown in Table I. Genomic DNAs obtained from colorectal cancer cell lines and crypt isolation samples were modified by sodium bisulfite and subjected to direct sequencing (19). A combined bisulfite restriction analysis (COBRA) (20) using an HpyCH4IV (New England Biolabs, Inc., Ipswich, MA) restriction site was also designed to determine CYP1B1 methylation status with a high degree of quantitative accuracy. A relative methylation level in each sample was visually determined by the density of each HpyCH4IVdigested band. The validity of the COBRA assay was con- firmed by bisulfite sequencing on at least 8 individual DNA strands after subcloning of PCR products into pCR4-TOPO vector using TOPO TA Cloning Kit for Sequencing (Invitrogen).

Quantitative real-time PCR analysis. Total RNA was isolated from cultured cells with RNeasy Mini Kit and DNase Set (Qiagen, Valencia, CA) following the manufacturer's protocol. mRNA levels of CYP1A1, CYP1B1, AhR, ARNT and ß-actin were evaluated by real-time PCR system 7500 (Applied Biosystems, Foster City, CA) using High Capacity cDNA Reverse Transcription Kit (Applied Biosystems) and FastStart Universal SYBR Green Master (ROX) (Roche, Basel, Switzerland). The primer sequences were described previously (21). Quantitative values were obtained from the threshold cycle $\left(C_{t}\right)$ number. The mRNA level of the target gene was normalized to its $B$-actin mRNA content for each sample. All samples were analyzed in duplicate and average quantities of the gene transcripts were used for calculation. Deviation of the mRNA level of each sample was within $7 \%$ of the average.

\section{Results}

DNA methylation of the CYP1B1 and CYP1A1 genes in colorectal cancer cell lines. Using $\mathrm{CpG}$ Island Searcher program, we found $\mathrm{CpG}$ islands within the 5' prime region of 
(a)

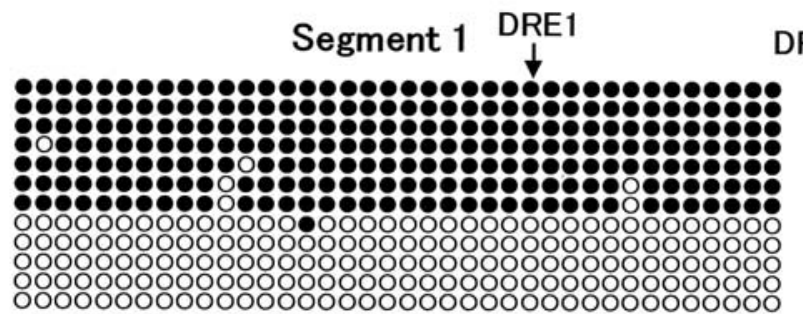

(b)

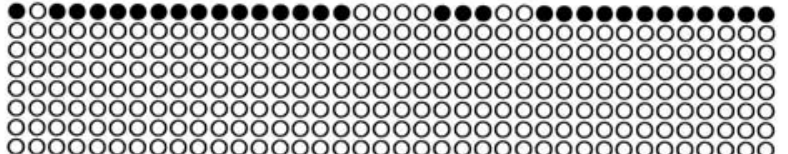

(c)

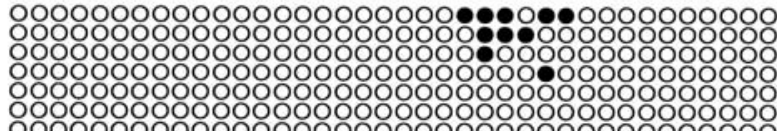
,

(d)

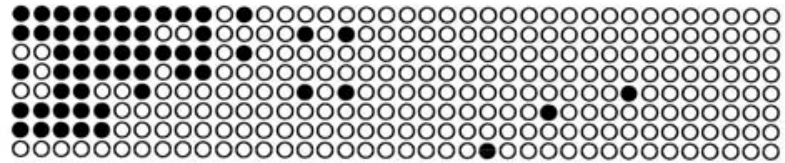

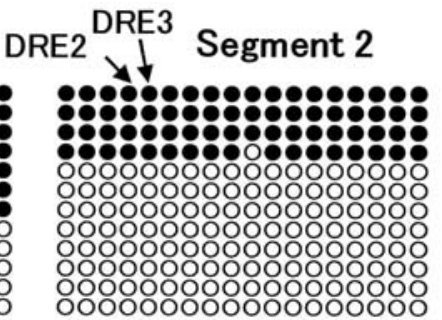
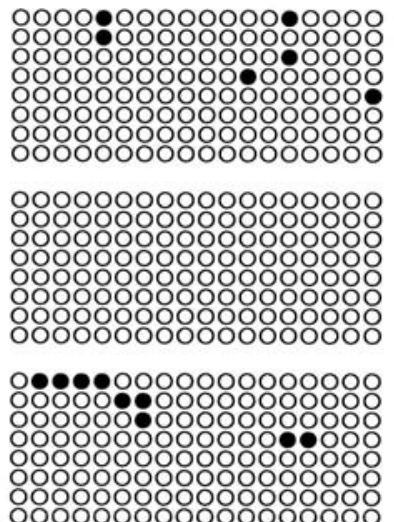

(a)

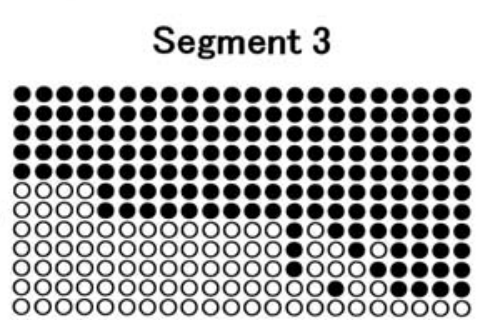

(b)

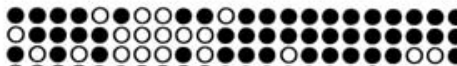

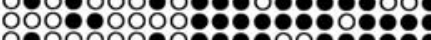

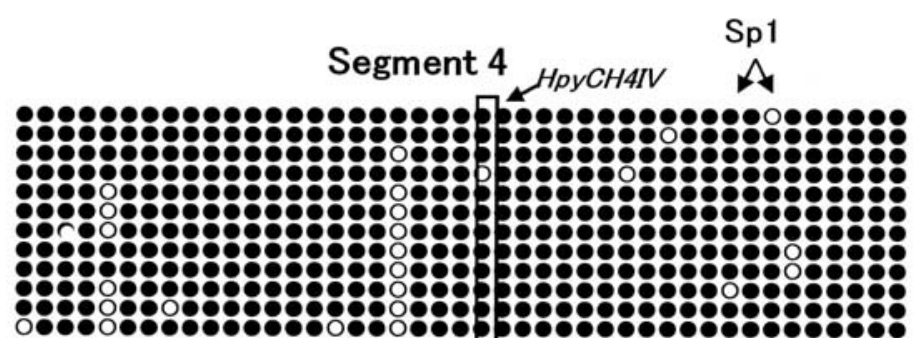

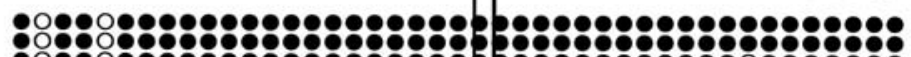

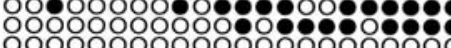

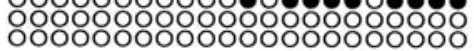

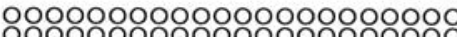

(c) 8.0000000000000000000 8. 8.

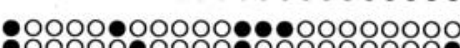

(d) (4) -1
l

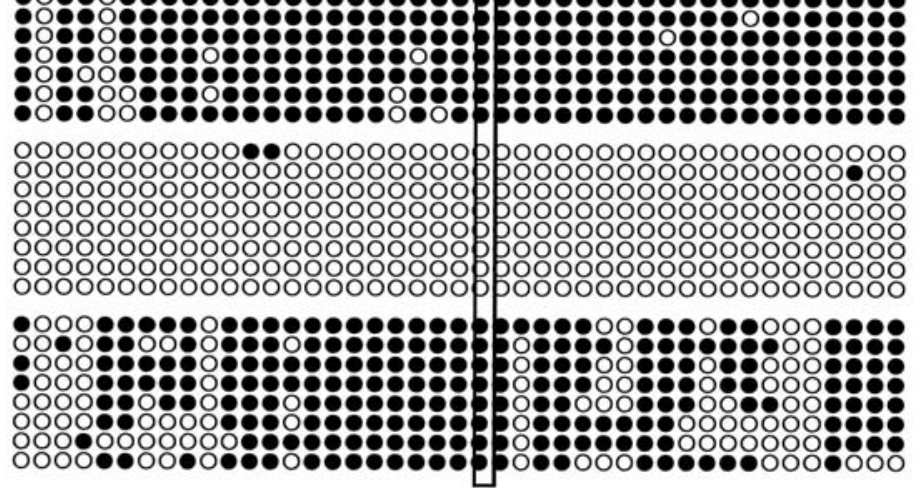

Figure 2. Summary of the results of bisulfite sequencing analysis of the four segments within the CYP1B1 gene. Methylation status of: (a), SW48 cells; (b), Caco-2 cells; (c), a normal tissue; and (d), a paired cancer tissue (showing methylation with the highest magnitude) are shown. Open and closed circles represent unmethylated and methylated $\mathrm{CpG}$ dinucleotides, respectively. The arrow with ' $H p y C H 4 I V$ ' indicates restriction site using COBRA assay.

the CYPIAl and CYPIBI genes (Fig. 1). DNA methylation status of these $\mathrm{CpG}$ islands was prescreened on a limited set of pilot samples ( 7 cancer cell lines and 3 pairs of cancer and normal tissues of colorectum). Bisulfite direct sequencing demonstrated that $C Y P 1 A 1$ gene methylation was exclusively detected in segment 1 , which is upstream of functional enhancer dioxin response elements (DREs 3-6) and promoter regions, and was consistent with a previous report (22). In addition, there were no apparent differences in the $\mathrm{CpG}$ methylation pattern among these samples. Therefore, $\mathrm{CpG}$ methylation of the CYPIAl gene might be tightly controlled and highly stable during colorectal carcinogenesis.
On the other hand, we found $C Y P 1 B 1$ gene methylation in two cell lines (SW48 and Caco-2) and one of the three cancer tissues, but none in the paired normal tissues. Bisulfite sequencing on each DNA strand revealed that methylation occurs throughout the $\mathrm{CpG}$ islands, including three DREs (enhancer) and two Sp1-binding sites (promoter) (23-25). In particular, $\mathrm{CpG}$ sites within the segment 4 , which encompasses these Sp1-binding sites, were the most densely methylated in these cell lines and the cancer tissue (Fig. 2a, b and d). Consequently, we determined $C Y P 1 B 1$ gene methylation status by COBRA assay using an $\mathrm{HpyCH} 4 \mathrm{IV}$ restriction site proximal to these Sp1-binding sites (see below). 
(a)

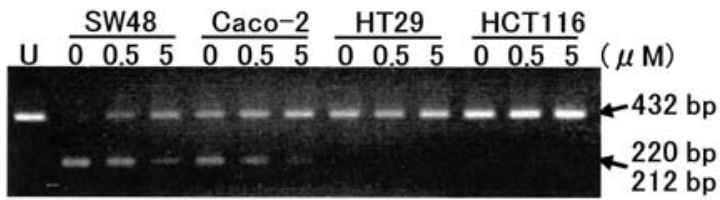

(b)

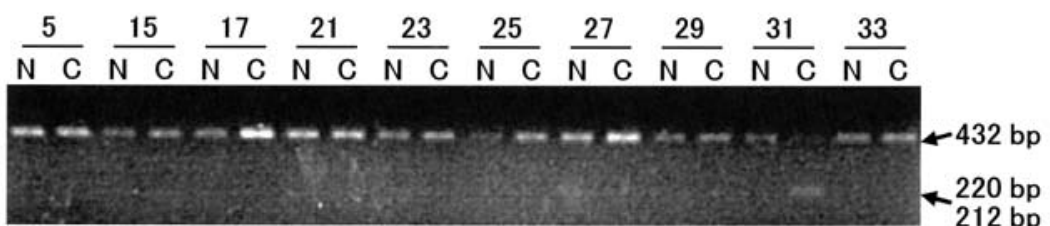

Figure 3. Methylation status of the CYP1B1 gene (segment 4, COBRA assay). (a) SW48, Caco-2, HT29 and HCT116 cells were treated with 5-aza-2'deoxycytidine $(0,0.5$ and $5 \mu \mathrm{M})$. A 432-bp band shows uncut (U) or unmethylated DNA, while 220/212-bp bands show methylated DNA. (b) Methylation status in ten primary colorectal cancers (numbers are those for particular cases). DNA samples from normal and cancer tissue are shown as $\mathrm{N}$ and $\mathrm{C}$, respectively. Note that a high degree of methylation was detected in cancer, but not in normal tissue of case 31 .

(a) CYP1B1

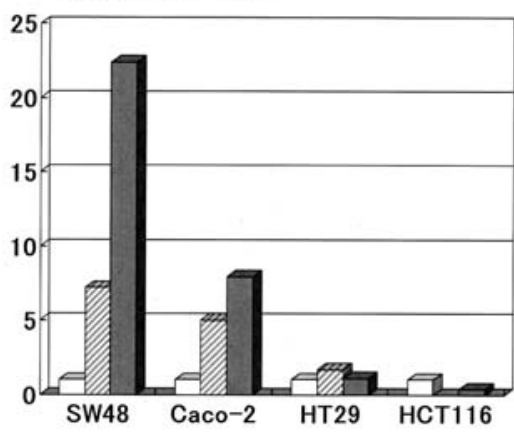

(c) AhR

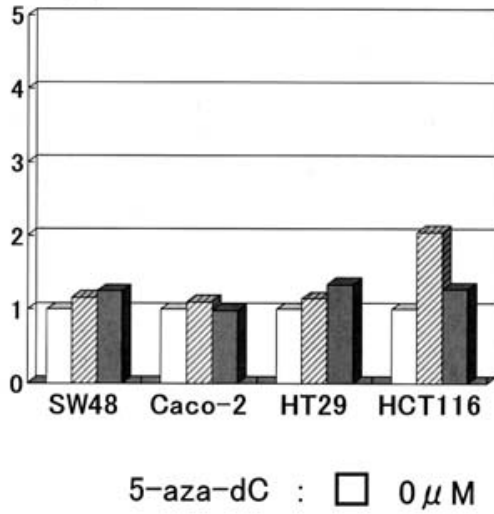

(b) CYP1A1

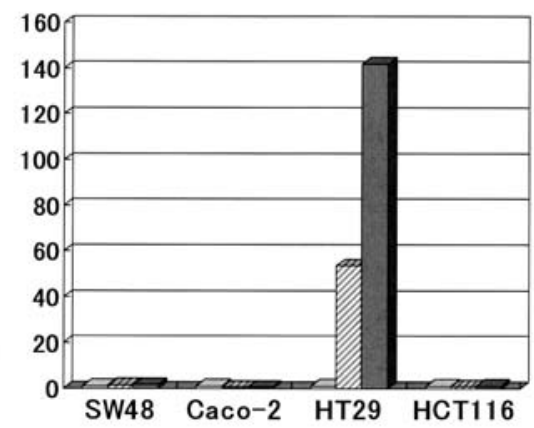

(d) ARNT

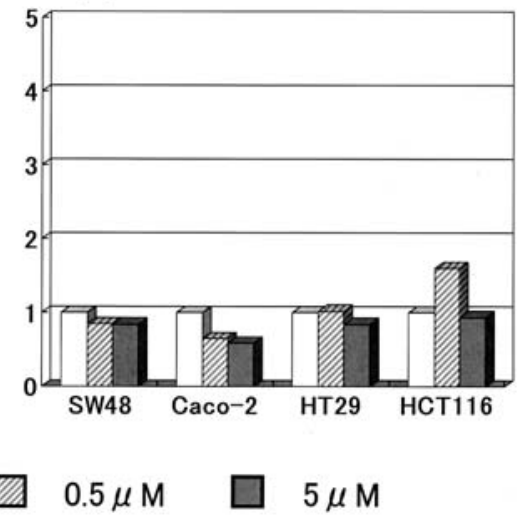

Figure 4 . Levels of: (a), CYP1B1; (b), CYP1A1; (c), AhR; and (d), ARNT transcripts (real-time PCR analysis). SW48, Caco-2, HT29 and HCT116 cells were treated with 5-aza-2'-deoxycytidine $(0,0.5$ and $5 \mu \mathrm{M})$. The vertical axis indicates a relative transcript level (ratio to cells without 5-aza-dC treatment).

Inhibition of DNA methylation and re-expression of the CYP1B1 gene by 5-aza-dC. In order to determine whether demethylation of the $\mathrm{CpG}$ sites resulted in re-expression of the $C Y P 1 B 1$ gene, cultured cells were treated with 0.5 or $5 \mu \mathrm{M}$ of 5-aza-dC. The COBRA assay revealed decreased amounts of methylated CYP1B1 alleles in SW48 and Caco-2 cells, and the decreased levels were dependent on the dose of 5-aza-dC
(Fig. 3a). Moreover, real-time PCR analysis showed an increase (recovery) in CYP1B1 transcripts in SW48 (7-22-fold increase) and Caco-2 (5-8-fold increase) cells in a dosedependent manner, but not in HCT116 and HT29 cells (Fig. 4a). Thus, the magnitude of methylation was associated with decreased levels of $C Y P 1 B 1$ gene expression. This also implied that methylation level of the HpyCH4IV sites could 
reflect the level of reduced expression of $C Y P 1 B 1$ gene. In contrast, 5-aza-dC had little effect on the constitutive levels of AhR and ARNT mRNAs in all cells examined (Fig. 4c and $d$ ). This result was supported by our findings that there was no $\mathrm{CpG}$ island in the 5' proximal upstream region of the AhR and ARNT genes. These results suggested that the CYP1B1 gene was transcriptionally downregulated in SW48 and Caco- 2 cells by direct methylation of their promoter/ enhancer $\mathrm{CpG}$ sites rather than AhR and/or ARNT downregulation.

On the other hand, HT29 cells showed a clear increase in CYP1A1 mRNA (more than 140-fold increase) after 5-aza-dC treatment (Fig. 4b). However, methylation status of the CYPIAl gene exhibited no differences among the four cell lines examined, suggesting that CYP1A1 expression was downregulated in HT29 cells by mechanisms other than its promoter methylation.

DNA methylation of the CYP1B1 gene in primary colorectal cancers. The methylation status of $C Y P 1 B 1$ gene was examined in 40 pairs of colorectal cancers and adjacent normal tissues by COBRA assay. Two cancer tissues (5\%) exhibited methylation in the promoter region, while none of the normal tissues showed methylation (Fig. 3b). Therefore, the $C Y P 1 B 1$ promoter was somatically hypermethylated in some colorectal cancers, and this likely led to transcriptional downregulation of $C Y P 1 B 1$ gene. There were no differences in clinicopathological findings between colorectal cancers with $C Y P 1 B 1$ methylation and those without methylation.

\section{Discussion}

In the present study, we found DNA hypermethylation of the 5' upstream region of the CYPIBI gene in colorectal cancer cell lines and primary cancers. In vitro studies using demethylating agent $(5-\mathrm{aza}-\mathrm{dC})$ revealed that the $C Y P 1 B 1$ gene was transcriptionally downregulated in cancer cells by direct methylation of their promoter/enhancer $\mathrm{CpG}$ sites. Previous studies demonstrated that CYP1B1 overexpression observed in lung carcinomas was associated with elevated expression of AhR (26). However, we found that CYP1B1 was not associated with relevant changes of AhR and ARNT expression in colorectal cancer cells. Therefore, DNA methylation likely interfered with the binding of AhR/ARNT heterodimer, or affected histone modifications and chromatin structure, which indirectly prevented transcription factor binding (15) in colorectal cancer cells. The previous study by others (26) and our study may suggest possible differences in tissue specific mechanisms of CYP1B1 expression between lung and colon cancers. The $\mathrm{CpG}$ sites around two Sp1-binding sites were most densely methylated in these cell lines and cancer tissue, suggesting that promoter methylation might play more critical roles in loss of CYP1B1 functions than enhancer methylation.

It is interesting that only HT29 cells showed a clear increase in CYP1A1 mRNA after 5-aza-dC treatment. There were no apparent differences in CYP1A1 methylation status among these cell lines. Moreover, DNA methylation could not be identified in segments 2 and 3 , which were known regulatory region and corresponded to cancer-specific methylation sites of prostate (27). Therefore, CpG methylation status of the CYP1A1 gene might be tightly controlled and highly stable, even during colorectal carcinogenesis. Consequently, downregulation of CYP1A1 in colorectal cancers resulted from promoter methylation of certain CYP1A1-regulatory factor(s) rather than CYP1A1 itself, although the mechanisms are still unclear.

We found $C Y P 1 B 1$ promoter methylation in 2 of $40(5 \%)$ primary colorectal cancers, but not in non-cancer tissues. The results reflected genuine DNA methylation status, because we examined pure cancer and normal epithelia using crypt isolation (19) and directly compared DNA methylation status between paired epithelia. We could not directly compare DNA methylation status with the CYP1B1 mRNA expression, because crypt isolation provided ethanol-fixed epithelia and it was difficult to obtain fresh mRNA samples. However, these cancer tissues exhibited a pattern of DNA methylation quite similar to that observed in SW48 and Caco-2 (Fig. 2). Therefore, the association between promoter methylation and transcriptional silencing of $C Y P I B 1$ gene is most likely applicable to primary colorectal cancers. It was recently demonstrated that $C Y P 1 B 1$ gene was hypermethylated in gastric cancers (28), while $C Y P 1 B 1$ gene was hypomethylated in prostate caners (17). Taken together with these studies, we suggest that aberrant expression of the CYPlB1 gene is commonly regulated by promoter methylation in human cancers, independent of hormone response. Previous studies demonstrated frequent CYP1B1 overexpression in colorectal cancers $(12,13)$. The CYP1B1 overexpression is, however, unlikely due to hypomethylation (demethylation) of the CYP1B1 promoter, because normal colon tissues never showed promoter methylation in the present study. Therefore, certain other mechanisms, such as microRNA downregulation observed in a breast cancer cell line (29), may be associated with CYP1B1 overexpression in colorectal cancers. The present study showed that a minor, but a significant subgroup of colorectal cancers did undergo downregulation of CYP1B1 through its promoter methylation. Interestingly, it was found that $\mathrm{AhR}$ was a putative $\mathrm{Wnt} / \mathrm{B}$-catenin target in prostate cancers (30). In addition, sulindac, one of the nonsteroidal anti-inflammatory drugs (NSAIDs), exerts its chemopreventive effects by inducing carcinogen metabolizing enzymes such as CYP1B1 through activating AhR (31). Therefore, aberrant expression of CYP1B1 by promoter methylation might play roles in colorectal carcinogenesis through Wnt/ß-catenin signaling pathway.

Cancer chemotherapy exhibits marked variability in drug response between individual patients. These differences mainly resulted from genetic polymorphisms of drugmetabolizing enzymes and drug transporters. For example, several genetic polymorphisms of UDP-glucuronosyltransferase 1A1 (UGT1A1), which acts as a detoxifier of irinotecan, provide clinically relevant determinants for predicting severe toxicity in cancer patients (32-35). On the other hand, drug response also depends on the biological characteristics of individual cancers, because cancer is highly heterogeneous by accumulating multiple genetic and epigenetic alterations. Indeed, downregulation of the UGT1A1 by promoter methylation occurred in cancer cells and can lead to increased toxicity of irinotecan (16). Therefore, we suggest that 
CYP1B1 methylation, similar to UGT1A1 methylation, can alter metabolic capacities of cancer cells and alter clinical response to chemotherapy. Although $C Y P 1 B 1$ methylation is not a common event in colorectal cancers in the present study, the CYP1B1 might play important roles in both cancer development and response to procarcinogen metabolism and chemotherapy in some colorectal cancers. Therefore, we suggest that molecular profiling of epigenetic DNA methylation status of drug-metabolizing enzymes, in combination with information of genetic polymorphisms, may better characterize cancers and provide more accurate prediction of drug response.

\section{Acknowledgements}

This work was supported by a Grant for Research on Publicly Essential Drugs and Medical Devices from The Japan Health Science Foundation. The authors thank Dr Paul Langman, for assistance with the preparation of this manuscript.

\section{References}

1. Jaiswal AK, Gonzalez FJ and Nebert DW: Human dioxininducible cytochrome P1-450: complementary DNA and amino acid sequence. Science 228: 80-83, 1985.

2. Sutter TR, Tang YM, Hayes CL, et al: Complete cDNA sequence of a human dioxin-inducible mRNA identifies a new gene subfamily of cytochrome P450 that maps to chromosome 2. J Biol Chem 269: 13092-13099, 1994.

3. Gonzalez FJ and Gelboin HV: Role of human cytochrome p450 in the metabolic activation of chemical carcinogens and toxins Drug Metab Rev 26: 165-183, 1994.

4. Denison MS, Fisher JM and Whitlock JP Jr: Protein-DNA interaction at recognition sites for the dioxin Ah-receptor complex. J Biol Chem 264: 16478-16482, 1989.

5. Reyes H, Reisz-Porszasz S and Hankinson O: Identification of the Ah receptor nuclear translocation protein (Arnt) as a component of the DNA binding form of the Ah receptor. Science 256: 1193-1195, 1992

6. Kress $S$ and Greenlee WF: Cell-specific regulation of human CYP1A1 and CYP1B1 genes. Cancer Res 57: 1264-1269, 1997.

7. Murray G, Melvin WT, Greenlee WF and Burke MD: Regulation, function, and tissue-specific expression of cytochrome P450 CYP1B1. Annu Rev Pharmacol Toxicol 41: 297-316, 2001.

8. Hayes C, Spink D, Spink B, Cao J, Walker N and Sutter T: 17ßestradiol hydroxylation catalyzed by human cytochrome P450 1B1. Proc Natl Acad Sci USA 93: 9776-9781, 1996.

9. Listgarten J, Damaraju S, Poulin B, et al: Predictive models for breast cancer susceptibility from multiple single nucleotide polymorphisms. Clin Cancer Res 10: 2725-2737, 2004.

10. Tanaka Y, Sasaki M, Kaneuchi M, Shiina H, Igawa M and Dahiya R: Polymorphisms of the CYP1B1 gene have higher risk for prostate cancer. Biochem Biophys Res Commun 296: 820-826, 2002.

11. Murray GI, Taylor MC, McFadyen MCE, McKay JA, Greenlee WF, Burke MD and Melvin WT: Tumor-specific expression of cytochrome P450 CYP1B1. Cancer Res 57: 3026-3031, 1997.

12. Kumarakulasingham M, Rooney PH, Dundas SR, Telfer C Melvin WT, Curran S and Murray GI: Cytochrome P450 profile of colorectal cancer: identification of markers of prognosis. Clin Cancer Res 11: 3758-3765, 2005.

13. Gibson P, Gill JH, Khan PA, et al: Cytochrome P450 (CYP1B1) is overexpressed in human colon adenocarcinomas relative to normal colon: implications for drug development. Mol Cancer Ther 2: 527-534, 2003.
14. Bethke L, Webb E, Sellick G, et al: Polymorphisms in the cytochrome P450 genes CYP1A2, CYP1B1, CYP3A4, CYP3A5, CYP11A1, CYP17A1, CYP19A1 and colorectal cancer risk. BMC Cancer 7: 123, 2007

15. Lund $\mathrm{AH}$ and van Lohuizen $\mathrm{M}$ : Epigenetics and cancer. Genes Dev 18: 2315-2335, 2004.

16. Gagnon J-F, Bernard O, Villeneuve L, Têtu B and Guillemette C: Irinotecan inactivation is modulated by epigenetic silencing of UGT1A1 in colon cancer. Clin Cancer Res 12: 1850-1858, 2006.

17. Tokizane T, Shiina H, Igawa M, et al: Cytochrome P4501B1 is overexpressed and regulated by hypomethylation in prostate cancer. Clin Cancer Res 11: 5793-5801, 2005

18. Habano W, Sugai T, Nakamura S and Yoshida T: A novel method for gene analysis of colorectal carcinomas using a crypt isolation technique. Lab Invest 74: 933-940, 1996.

19. Habano W, Sugai T, Jiao YF and Nakamura S: Novel approach for detecting global epigenetic alterations associated with tumor cell aneuploidy. Int J Cancer 121: 1487-1493, 2007.

20. Xiong $\mathrm{Z}$ and Laird PW: COBRA: a sensitive and quantitative DNA methylation assay. Nucleic Acids Res 25: 2532-2534, 1997.

21. Chang H, Chang LW, Cheng Y-H, Tsai W-T, Tsai M-X and Lin P: Preferential induction of CYP1A 1 and CYP1B1 in CCSP-positive cells. Toxicol Sci 89: 205-213, 2006.

22. Kress S, Reichert J and Schwarz M: Functional analysis of the human cytochrome P450A1 (CYP1A1) gene enhancer. Eur J Biochem 258: 803-812, 1998.

23. Wo Y-YP, Stewart J and Greenlee WF: Functional analysis of the promoter for the human CYP1B1 gene. J Biol Chem 272: 26702-26707, 1997.

24. Shehin SE, Stephenson RO and Greenlee WF: Transcriptional regulation of the human CYP1B1 gene: Evidence for involvement of an aryl hydrocarbon receptor response element in constitutive expression. J Biol Chem 275: 6770-6776, 2000.

25. Tsuchiya $Y$, Nakajima $M$ and Yokoi T: Critical enhancer region to which AhR/ARNT and Sp1 bind in the human CYP1B1 gene. J Biochem 133: 583-592, 2003.

26. Chang JT, Chang H, Chen PH, Lin S-L and Lin P: Requirement of aryl hydrocarbon receptor overexpression for CYP1B1 upregulation and cell growth in human lung adenocarcinomas. Clin Cancer Res 13: 38-45, 2007.

27. Okino ST, Pookot D, Li L-C, et al: Epigenetic inactivation of the dioxin-responsive cytochrome P4501Al gene in human prostate cancer. Cancer Res 15: 7420-7428, 2006.

28. Kang GH, Lee S, Cho NY, et al: DNA methylation profiles of gastric carcinoma characterized by quantitative DNA methylation analysis. Lab Invest 88: 161-170, 2008.

29. Tsuchiya Y, Nakajima M, Takagi S, Taniya T and Yokoi T: MicroRNA regulates the expression of human cytochrome P450 1B1. Cancer Res 66: 9090-9098, 2006.

30. Chesire DR, Dunn TA, Ewing CM, Luo J and Isaacs WB: Identification of aryl hydrocarbon receptor as a putative wnt/ß-catenin pathway target gene in prostate cancer cells. Cancer Res 64: 2523-2533, 2004.

31. Ciolino HP, Bass SE, MacDonald CJ, Cheng RYS and Yeh GC: Sulindac and its metabolites induce carcinogen metabolizing enzymes in human colon cancer cells. Int J Cancer 122: 990-998, 2008.

32. Ando Y, Saka H, Ando M, et al: Polymorphisms of UDPglucuronosyltransferase gene and irinotecan toxicity: a pharmacogenetic analysis. Cancer Res 60: 6921-6926, 2000.

33. Iyer L, Das S, Janisch L, et al: UGT1A $1 * 28$ polymorphism as a determinant of irinotecan disposition and toxicity. Pharmacogenomics J 2: 43-47, 2002.

34. Rouits E, Boisdron-Celle M, Dumont A, Guérin O, Morel A and Gamelin E: Relevance of different UGT1A1 polymorphisms in irinotecan-incuced toxicity: a molecular and clinical study of 75 patients. Clin Cancer Res 10: 5151-5159, 2004.

35. Sai K, Saito Y, Sakamoto H, et al: Importance of UDP. glucuronosyltransferase $1 A 1^{*} 6$ for irinotecan toxicities in Japanese cancer patients. Cancer Lett 261: 165-171, 2008. 